\title{
RELACIÓN DE EVALUADORES
}

La Revista de Española de Salud Pública ha contado en su proceso editorial para este número monográfico con la colaboración de expertos en metodología cualitativa, quienes, de forma anónima e independiente, han actuado como evaluadores externos de los trabajos que se han recibido solicitando su publicación. Su contribución desinteresada ha sido fundamental, por lo que el Comité de Redacción les agradece de forma muy especial su colaboración.

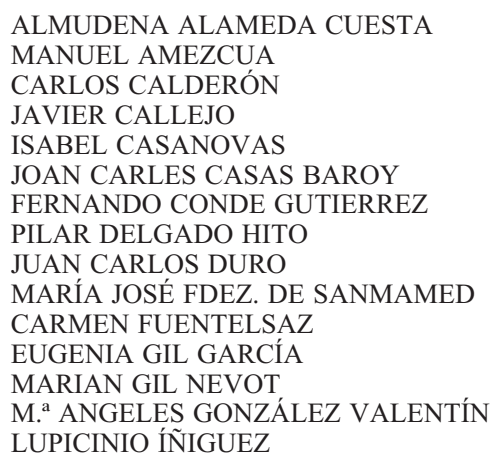

ELENA DE LORENZO

EMILIO LUCIO-VILLEGAS RAMOS

JOAN CARLES MARCH CERDÁ

INMACULADA MATEO RODRIGUEZ

ARACELI MONZÓN FERNÁNDEZ

ANSELMO PEINADO

MARGARIDA PLA

M. a ANGELES PRIETO

MILAGROS RAMASCO

JUANA ROBLEDO MARTÍN

MANUEL JESÚS SALAS IGLESIAS

MODESTA SALAZAR AGULLÓ

LUIS SEOANE

CARMEN SILVESTRE 